\title{
As transformações do programa institucional de bolsas de iniciação à docência a partir da análise de seus editais
}

\author{
The transformations of the institutional scholarship program for initiation to \\ teaching from the analysis of its public notices
}

Elciane de Jesus Santos

Mestranda em Educação Ciências e Matemática Universidade Estadual do Sudoeste da Bahia - UESB

Jequié, BA - Brasil elcyane1@hotmail.com

\author{
Daisi Teresinha Chapani \\ Doutora em Educação em Ciências \\ Universidade Estadual do Sudoeste da Bahia - UESB. \\ Jequié, BA - Brasil \\ dt.chapani@gmail.com
}

Resumo: Este artigo apresenta os resultados da análise dos editais do Programa Institucional de Bolsas de Iniciação à Docência (Pibid), publicados entre os anos de 2007 e 2020, assinalando as modificações ocorridas nestes documentos, a fim de se verificar possíveis tendências. A metodologia utilizada foi a análise documental, a partir de uma abordagem quali-quantitativa. Os resultados mostram que, a despeito do impacto positivo do Pibid nas licenciaturas, nas escolas de educação básica e na formação docente, o Programa vem passando por um processo de encolhimento, fragmentação e instrumentalização.

Palavras chave: formação docente; pibid; políticas públicas.

Abstract: This paper presents the results of the Institutional Program for Teaching Initiation Scholarships (Pibid) public notices analysis, which were published between the years 2007 and 2020, pointing out the changes that occurred in these public notices, in order to verify possible trends. The methodology used was document analysis, based on a qualitative and quantitative approach. The results show that, despite the positive impact that Pibid has in undergraduate courses, in basic education schools and in teacher training, the Program has been going through a process of shrinking, fragmentation and instrumentalization.

Key-words: teacher education; teacher training programs; public polices.

Cite como

(ABNT NBR 6023:2018)

SANTOS, Elciane de Jesus; CHAPANI, Daisi Teresinha. As transformações do programa institucional de bolsas de iniciação à docência a partir da análise de seus editais. Dialogia, São Paulo, n. 38, p. 1-14, e19620, maio/ago. 2021. Disponível em: https://doi.org/10.5585/38.2021.19620.

American Psychological Association (APA)

Santos, E. de. J., \& Chapani, D. T. (2021, maio/ago.). As transformações do programa institucional de bolsas de iniciação à docência a partir da análise de seus editais. Dialogia, São Paulo, 38, p. 1-14, e19620. https:/ /doi.org/10.5585/38.2021.19620. 


\section{Introdução}

O Programa Institucional de Bolsas de Iniciação à Docência (Pibid) é uma iniciativa do Ministério da Educação (MEC) para o aperfeiçoamento da formação de professores para a Educação Básica. É um programa de fomento, que concede bolsas para alunos de licenciatura, participantes de projetos de iniciação à docência, e para professores de educação básica e superior, sendo desenvolvido por Instituições de Educação Superior (IES), em parceria com escolas de Educação Básica da rede pública de ensino. O Programa promove a inserção dos licenciandos nas escolas, desde o início de sua formação acadêmica, para o desenvolvimento de atividades didáticopedagógicas, sendo eles orientados por um docente universitário e supervisionados por um professor da escola pública.

São participantes do Pibid: discentes de licenciatura; professores de escolas públicas da educação básica, que atuam como supervisores; docentes de cursos de licenciatura, que coordenam os subprojetos; e professor de licenciatura que coordena o projeto institucional nas Instituições de Ensino Superior (IES).

Criando em 2007, o Pibid foi se consolidando como uma importante ação relacionada às políticas de formação docente devido ao seu caráter inovador e à sua abrangência. Diversos relatórios (BRASIL, 2013d, 2015; GATTI et al., 2014) e uma vastíssima produção acadêmica (CHAPANI; LUZ, 2018; NOGUEIRA; FERNANDEZ, 2018; OLIVEIRA; ALGEBAILE, 2019; FETZNER, 2018; VILLAS BÔAS; D'AVILA; MARTINS, 2016, entre outros) atestam a importância do Pibid para: a melhoria da formação profissional de docentes da educação básica e superior; a construção da identidade docente; o estreitamento das relações entre escolas e IES formadoras; a dinamização das atividades didáticas nas escolas; a valorização dos cursos de licenciatura, entre outros aspectos. Tais estudos também apontam as insuficiências, limitações e necessidades de aprimoramento do Programa, como por exemplo: o excesso de burocracia, o baixo valor da verba de custeio, alta rotatividade de bolsistas etc.

Além das evidências empíricas, que demonstram o impacto positivo do Pibid na formação docente, o Programa encontra respaldo em diversas normas legais, tais como: a portaria normativa do Ministério da Educação 30/2007, formulada em consonância com o primeiro edital; o decreto 7.219/2010, que regulamentou o Pibid, apresentando seus objetivos e estrutura; e a lei 12.796/2013, que alterou a Lei de Diretrizes e Bases da Educação Nacional (lei 9.394/1996), incluindo a determinação que a União e demais entes federados incentive a "a formação de profissionais do magistério para atuar na educação básica pública mediante programa institucional de bolsa de iniciação à docência", entre outras normativas que citaremos no decorrer do artigo. 
No entanto, o principal instrumento para sua implementação é o edital de fomento. Desde sua criação até este momento, foram lançados 10 editais do Pibid que, embora tenham mantido a estrutura básica de concessão de bolsas, foram se modificando no decorrer dos anos. Nesse sentido, questionamos: quais foram as mudanças mais significativas ocorridas nesses editais? É possível delinear alguma tendência? Se sim, qual? Que tipo de relação é possível estabelecer entre os editais do Pibid e outras políticas públicas?

Convém destacar que Rodrigues, Silva e Miskulin (2014) já haviam realizado uma análise desses documentos, até o edital de 2013, porém, neste artigo pretendemos atualizar o estudo até o edital de 2020 e discutir outros aspectos não contemplados pelo trabalho precedente.

\section{Modelos de formação docente}

Ao longo da história, a formação dos responsáveis pelo ensino apresentou diferentes configurações. Contudo, desde o século XIX, vem se firmando a ideia da necessidade de uma formação específica, longa e fundamentada em preceitos científicos para os professores (NÓVOA, 1999).

Assim, foi se instituindo de forma hegemônica, modelos formativos fundamentados na racionalidade técnica, pautando-se na premissa que as questões educacionais devem ser enfrentadas a partir de uma perspectiva racional, utilizando-se de instrumentos ditados pela ciência. Esses modelos têm como características: o ensino de conteúdos desconectados da realidade profissional; o treinamento de habilidades; e o entendimento da prática como mera instância de aplicação da teoria (CARR; KEMMIS, 1988; DINIZ- PEREIRA, 2002). De maneira que se estabeleceu de forma muito clara os tempos e espaços da formação docente: primeiro deve-se aprender os aspectos teóricos da profissão (nos centros especializados de formação) e depois aplicar esse conhecimento no contexto da prática (escolas de educação básica).

No entanto, tal abordagem vem sofrendo críticas desde a primeira metade do século XX, sendo que, a partir década de 1980, um amplo movimento consolidou as bases para a constituição de modelos formativos fundamentados na racionalidade prática (SCHÖN, 1995), que valorizam os saberes docentes (TARDIF, 2012) e que levam em consideração a subjetividade do professor (NÓVOA, 1999).

Teorias críticas também desvelaram as inconsistências epistemológicas da racionalidade técnica, caraterizada por separar teoria e prática. Denunciaram, no entanto, que os modelos fundamentados na racionalidade prática, ao focarem no método e secundarizarem o contexto 
social, fazem-se insuficientes para superação das desigualdades e da opressão (CARR; KEMMIS, 1988; DINIZ- PEREIRA, 2002).

Vemos assim, que o Pibid se situa nessa tentativa de superação da racionalidade técnica, fundamentando-se em perspectivas práticas e críticas para sustentar a defesa da escola como espaço legítimo de formação, os professores de educação básica como portadores e produtores de saberes da docência, a possibilidade de aprendizagem mútua no coletivo formado pelos licenciandos, docentes universitários e professores de educação básica, além da necessária interconexão entre pesquisa e ensino. De modo que, “o processo de modificação e (re)construção de uma nova cultura educacional que se pretende alcançar com o Pibid é pautado em pressupostos teóricometodológicos que articulam teoria-prática, universidade-escola e formadores-formandos" (BRASIL, 2013d, p. 29).

\section{Metodologia}

Utilizamos a análise documental como procedimento metodológico. Para Pimentel (2001, p. 179) as pesquisas que têm "documentos como material primordial [...] extraem deles toda a análise, organizando-os e interpretando-os segundo os objetivos da investigação proposta”.

No caso deste trabalho, a análise foi realizada primordialmente sobre os editais do Pibid (BRASIL, 2009, 2010a, 2010b, 2011, 2012, 2013a, 2013b, 2018, 2020b). Para complementação dos dados, utilizou-se também: o edital do Programa Residência Pedagógica (BRASIL, 2020a), uma vez que este programa apresenta relação com o Pibid; relatórios elaborados pela Capes disponíveis na internet (BRASIL, 2013c, 2013d, 2015; GATTI et al., 2014; RUIZ; RAMOS; HINGEL, 2007); além de outras publicações que tratam do assunto, conforme citadas no texto.

Fizemos uso de dados qualitativos (objetivos do Programa, segundo cada edital, e informações gerais obtidas em diversas fontes) e quantitativos (número de bolsas oferecidas). Os resultados são apresentados e discutidos no próximo tópico, o qual se encontra organizado em dois subtópicos: i) contextualização histórica dos editais e as relações do Pibid com outras políticas públicas; ii) possíveis tendências extraídas da análise dos editais do Pibid.

\section{Resultados e discussões}

\subsection{Contextualização histórica dos editais e as relações do Pibid com outras politicas públicas}

Para desenvolvermos nossas análises a respeito das transformações do Pibid, é importante contextualizar seu surgimento, em 2007. Segundo Lima e Silva (2019), as políticas de formação desencadeadas naquele período foram marcadas pela diversidade, pela flexibilização, por ações 
emergenciais e pela expansão das matrículas em cursos de licenciatura. Nesse contexto, uma série de iniciativas foi implementada a fim de aumentar o acesso ao ensino superior, em especial, dos alunos provenientes das camadas populares.

Essas políticas relacionavam-se com outras, como políticas de educação básica e para a juventude.

Dentro do clima de preocupações com a juventude e com sua escolarização, o Conselho Nacional de Educação - CNE - designou uma comissão interna para realizar um estudo sobre o Ensino Médio e a falta de professores qualificados em algumas áreas do conhecimento. O resultado foi divulgado em um relatório [...] com o título: Escassez de professores no ensino médio: propostas estruturais e emergenciais. (BIT'TENCOURT, 2008, p. 7).

O relatório citado fazia diversas considerações sobre o ensino médio no Brasil, apontando a falta de professores como um dos principais fatores limitantes para a expansão e a melhoria deste nível de ensino. O documento apresentou uma série de recomendações visando sanar tais problemas, muitas das quais efetivamente constituíram-se como políticas públicas. Entre essas sugestões, consta:

de imediato, o MEC deverá implantar um programa de bolsas de incentivo à docência
para os alunos desses cursos licenciaturas], nos mesmos moldes da iniciação científica,
que tanto vem contribuindo para o desenvolvimento científico e tecnológico do país.
Essa atitude significa valorizar o futuro professor e despertar a motivação das
universidades pela educação básica, e também aumentaria a demanda pelos cursos de
Licenciatura, com impacto direto na qualidade discente. (RUIZ; RAMOS; HINGEL,
2007, p. 22).

De fato, em dezembro de 2007, o MEC, a Fundação Coordenação de Aperfeiçoamento de Pessoal de Nível Superior (Capes) e o Fundo Nacional de Desenvolvimento da Educação (FNDE) apresentaram o primeiro edital do Pibid. O Programa só iniciou efetivamente suas ações em 2009 (BRASIL, 2013d), porém, como estamos nos atendo à análise dos editais, consideramos o ano de seu lançamento.

A participação da Capes como fomentadora das ações do Pibid deveu-se à transformação nas suas funções ocorridas por meio da lei 11.502/2007, conforme esclarecem Costa e Duran:

A Capes, agência de fomento até então voltada para a pesquisa e a formação de pessoal de alto nível no País, a partir da promulgação da Lei no 11.502 e sob regulamentação da portaria $\mathrm{n}^{\mathrm{o}} 609$, de 20 de maio de 2008, passou a contar com o Conselho TécnicoCientífico da Educação Básica (CTC-EB) e as Diretorias de Educação Básica Presencial (DEB) e de Educação a Distância (DED), voltando sua atenção para a Política Nacional de Formação de Professores: eis a nova Capes. (COSTA; DURAN, 2012, p. 279). 
Notamos, assim, a construção de uma estrutura voltada para a formação docente em nível superior, que se apoiou em diagnóstico dos problemas, propostas de solução, mudanças na legislação e amparo financeiro.

Nesse contexto, foram criados diversos programas que, de forma direta ou indireta, possibilitavam o fortalecimento das licenciaturas e ampliavam a oferta de vagas desses cursos em instituições públicas. Além do Pibid, podemos citar: Programa de Apoio a Planos de Reestruturação e Expansão das Universidades Federais (Reuni) e o Programa de Consolidação das Licenciaturas (Prodocência) (BRASIL, 2013c; HADDAD, 2008).

Esse conjunto de ações relacionadas às políticas educativas e, em especial, as direcionadas à educação superior e à formação docente, traziam como um dos princípios sua estreita vinculação com as escolas de educação básica (HADDAD, 2008). Nesse sentido, já no primeiro edital, o Pibid apresentava como um de seus objetivos: "estimular a integração da educação superior com a educação básica no ensino fundamental e médio, de modo a estabelecer projetos de cooperação que elevem a qualidade do ensino nas escolas da rede pública” (BRASIL, 2007, p. 2).

Levando-se em consideração o diagnóstico apresentado no relatório "Escassez...” (RUIZ; RAMOS; HINGEL, 2007), o edital de 2007 (BRASIL, 2007) contemplou a formação inicial de professores para atuarem no ensino médio e nos anos finais do ensino fundamental, nas disciplinas de física, química, matemática, biologia e ciências e, de forma complementar, língua portuguesa, educação musical e educação artística.

As instituições elegíveis para a apresentação de projetos eram as "federais de ensino superior e centros federais de educação tecnológica que [possuíssem] cursos de licenciatura com avaliação satisfatória no Sistema Nacional de Avaliação da Educação Superior.” (BRASIL, 2007, p. 2). Nesse sentido, o Pibid encontrava-se em sinergia com o Reuni. No primeiro edital do Pibid, as bolsas tinham duração de 12 meses e era possível financiamento de despesas de custeio para a execução do projeto.

Outro aspecto a ser enfatizado é que, desde o primeiro edital, atribuiu-se ao Pibid o propósito de fomentar práticas inovadoras, especialmente com o uso de ferramentas proporcionadas pelas novas tecnologias de informação e comunicação (BRASIL, 2007).

Em 2009, foi publicado o decreto da Política Nacional de Formação de Profissionais do Magistério da Educação Básica (decreto no 6.755/2009) que, entre outros aspectos que enfeixaram e direcionaram as políticas de formação docente do período, apresentou explicitamente a determinação de que o MEC apoiasse ações de formação inicial e continuada de professores, inclusive por meio de concessão de bolsas. Assim, o segundo edital respaldava-se em um 
instrumento legal mais sólido que a portaria normativa que fundamentou o primeiro, muito embora, o decreto que viria a regulamentar o Pibid (decreto 7.219/2010) só tenha sido publicado no ano seguinte.

Os objetivos apresentados no edital de 2009 eram praticamente os mesmos que os do anterior. Demonstrando a intenção de expansão do Programa, possibilitou-se a participação não apenas de IES federais, mas também as públicas estaduais. Além disso, foi ampliado o rol de licenciaturas, passando a incluir cursos de filosofia, sociologia, letras: língua estrangeira, pedagogia e "licenciaturas com denominação especial que atendam a projetos interdisciplinares ou novas formas de organização" dos ensinos fundamental e médio (BRASIL, 2009, p. 5), o que possibilitou a realização de projetos em diversos níveis e modalidades de ensino. Uma vez que o prazo de execução dos projetos era de 24 meses, as bolsas tinham esse mesmo tempo de duração.

Como já indicado, em 2010 foi publicado o decreto 7.219/2010, sendo que "a substituição das portarias que regulamentavam o Pibid" por este decreto "sinalizou a preocupação do Ministério da Educação com a institucionalização do programa, com sua consolidação e com sua continuidade na agenda das políticas públicas educacionais.” (BRASIL, 2013d, p.28).

No ano de 2010, foram lançados dois editais do Pibid. O edital 02/2010 (BRASIL, 2010a), relativo ao Pibid-diversidade, visava fomentar projetos envolvendo as licenciaturas de educação no campo e educação indígena. Já o edital 18/2010 (BRASIL, 2010b) destinava-se a projetos envolvendo as licenciaturas já abarcadas pelos editais anteriores. Nesse sentido, praticamente todos os cursos de licenciatura passaram a ser contemplados pelos editais do Pibid.

Os objetivos de ambos os editais são semelhantes entre si e em relação aos de 2007 e 2009. Uma diferença foi a vinculação das ações do Pibid com os processos de avaliação externa, como se nota no seguinte trecho:

proporcionar aos futuros professores participação em experiências metodológicas, tecnológicas e práticas docentes de caráter inovador e interdisciplinar e que busquem a superação de problemas identificados no processo de ensino-aprendizagem, levando em consideração o IDEB e o desempenho da escola em avaliações nacionais, como Provinha Brasil, Prova Brasil, SAEB, ENEM, entre outras. (BRASIL, 2010a, b, p. 3 , grifos nosso).

Outra mudança importante foi a inclusão das IES municipais e comunitárias sem fins lucrativos entre as elegíveis a apresentarem projetos.

O prazo de execução dos projetos contemplados em ambos os editais era de 48 meses, ampliando-se a vigência das bolsas até o limite deste prazo. 
Em 2012 foi lançado um edital para bolsas e verbas de custeio, com prazo de execução de um ano, prorrogável por mais um ano, complementar aos projetos que já estavam em andamento ou para novos projetos. Não houve mudanças significativas em relação ao edital anterior.

Em 2013 foram publicados dois editais: um para as licenciaturas em geral e outro no âmbito do Pibid-diversidade (BRASIL, 2013a, b). Nesses editais houve ampliação das IES elegíveis, passando a contemplar, além das públicas, comunitárias e privadas sem fins lucrativos, também as IES privadas com fins lucrativos, com a finalidade de atender aos licenciandos beneficiários do Programa Universidade para Todos (ProUni). A essas IES, no entanto, era vetada o financiamento de despesas de custeio, aberto apenas às demais.

Com a expansão do Programa, houve aumento significativo dos recursos destinados à sua manutenção. Segundo consta no Relatório de Gestão 2009-2014 (BRASIL, 2013d), em 2009 o investimento no pagamento de bolsas e verbas de custeio era de pouco mais de 20 milhões de reais, subindo para quase 288 milhões em 2013.

Embora o edital 07/2018 tenha mantido a estrutura geral do Pibid, bem como seus objetivos centrais, foram introduzidas diversas mudanças em virtude da criação de do Programa de Residência Pedagógica (PRP).

Com modelo muito próximo ao do Pibid, o PRP foi criado por meio da portaria Capes 38/2018, com quatro objetivos, sendo dois deles já consagrados, que seriam os de aperfeiçoar a formação dos licenciandos, por meio de projetos centrados na prática profissional, e fortalecer as relações entre IES e escolas de educação básica, estimulando a participação das redes de ensino na formação docente. Além disso, foi atribuído ao PRP: induzir a reformulação do estágio curricular supervisionado e promover a adequação dos currículos das licenciaturas às orientações da Base Nacional Comum Curricular (BNCC) (BRASIL, 2018b).

Assim sendo, em 2018, o edital do Pibid apresentava como seu público-alvo os "discentes que estejam na primeira metade de curso de licenciatura, ofertado por IES pública ou privada sem fins lucrativos, na modalidade presencial ou no âmbito do Sistema Universidade Aberta do Brasil (UAB)" (BRASIL, 2018, p. 1). Em virtude desta restrição, também foi diminuída a duração de bolsas, que passou a ser de até 18 meses.

Em 2019 foi publicada a portaria Capes 259 com o propósito de regulamentar o PRP e o Pibid. Esse documento especificou que o objetivo de "promover a adequação dos currículos e propostas pedagógicas dos cursos de licenciatura às orientações da Base Nacional Comum Curricular" (art. $5^{\circ}$, inciso ii) era específico do PRP. Assim sendo, o edital do Pibid de 2020 deixou de conter essa determinação. 
Os editais de 2018 e 2020 não financiaram verbas de custeio. Além disso, o número de bolsas ofertadas era menor que o necessário para a constituição dos núcleos de iniciação à docência, implicando na participação de voluntários, conforme consta, por exemplo, no tópico 5.3 do edital de 2018 (BRASIL, 2018): “serão disponibilizadas pelo menos 24 cotas de bolsa na modalidade de iniciação à docência por núcleo. Para completar o número de 30 discentes, a IES será incentivada a incluir participantes sem bolsa."

Outro dado que consideramos importante enfatizar é que o edital de 2020 destacou como áreas prioritárias de iniciação à docência: língua portuguesa, matemática, ciências, física, química, biologia e alfabetização (BRASIL, 2018), aproximando-se do que constava no primeiro edital.

Vemos, portanto, que nos últimos anos o Pibid tem passado por diversas alterações, expressas nos dois últimos editais. Contudo, há indicativos que,

[essas] mudanças podem provocar o distanciamento do PIBID de sua identificação com a iniciação à docência, pois prejudicam a eficiência da ação de tutoria, diminuem a heterogeneidade dos sujeitos que compõem os subprojetos e enfraquecem as parcerias entre universidades e escolas. Além disso, não contribuem para diminuir as limitações desse Programa e não ampliam as possibilidades dos futuros professores de vivenciarem os diversos elementos que caracterizam o início da docência (RABELO; DIAS; CARVALHO, 2020).

\subsection{Possiveis tendências extraídas da análise dos editais do Pibid.}

$\mathrm{Da}$ análise dos editais e relatórios do Pibid, extraímos duas principais tendências que, a nosso ver, demostram um enfraquecimento do Programa a partir de 2018: i) a redução do número de bolsas e ii) retrocesso na perspectiva formativa.

\subsubsection{Evolução do número de bolsas}

Na Tabela 1 está sintetizado o número total bolsas concedidas relativas a cada edital, incluindo as de iniciação à docência, de supervisão e de coordenação.

Tabela 1 - Número de bolsas concedidas relativas a cada um dos editais Pibid

\begin{tabular}{|c|c|c|c|c|c|c|c|c|}
\hline & \multicolumn{8}{|c|}{ Editais } \\
\hline & 2007 & 2009 & 2010 & 2011 & 2012 & 2013 & 2018 & 2020 \\
\hline $\begin{array}{l}\mathbf{N}^{\circ} \text { bolsas } \\
\text { aprovadas }\end{array}$ & 3.088 & 10.606 & 3.020 & 13.292 & 22.403 & 90.254 & 45.000 & 30.096 \\
\hline
\end{tabular}

Fonte: Os dados foram extraídos dos respectivos editais e do relatório da Diretoria de Formação de Professores da Educação Básica - DEB (BRASIL, 2013d).

O número de bolsas apresentado na Tabela 1 refere-se exclusivamente aos editais Pibid e Pibid-diversidade, porém, devemos nos lembrar que nos anos de 2018 e 2020 foram lançados também editais do PRP, oferendo um número de bolsas equivalente aos editais do Pibid. 
Assim, é facilmente percebido que de 2007 a 2013 houve um grande aumento do número de bolsas concedidas. No edital de 2018, podemos ver que esse quantitativo foi reduzido pela metade, se considerarmos apenas o Pibid, ou que ele permaneceu estável, considerando-se as bolsas do Pibid mais as do PRP. Porém, em 2020, é inequívoca a redução, de aproximadamente 67\% considerando-se apenas as bolsas do Pibid ou, mesmo somando-se com as bolsas de PRP, de pelo menos 33\%. Esclarecemos que o edital de 2020 foi elaborado durante o ano de 2019 e lançado em janeiro de 2020, não guardado, portanto, relação com o contexto pandêmico.

Além disso, a partir do edital de 2018, houve aumento do número de licenciando sob orientação de supervisores, fazendo com que diminuísse o número de professores de educação básica vinculados ao programa e aumentasse a carga de trabalho desses profissionais.

\subsubsection{Perspectivas de formação docente}

A palavra inovação e/ou seus derivados estão presentes em todos os editais do Pibid. Mais do que estimular o desenvolvimento de metodologias inovadoras, o Pibid pode ser considerado, ele próprio, uma inovação no campo da formação docente ao buscar superar a racionalidade técnica, criando condições para que coletivos locais de professores-pesquisadores estudem a realidade concreta das escolas em que os projetos estavam inseridos, levantem problemas e busquem soluções. Inúmeras pesquisas mostram o acerto dessa proposta, apesar de algumas dificuldades e limitações (CHAPANI; SANTOS; RIBEIRO, 2016; FETZNER, 2018; GATTI et al., 2014; NOGUEIRA; FERNANDEZ, 2019).

No entanto, em 2018, o edital explicita a pretensão de controle do currículo escolar ao condicionar os projetos do Pibid aos objetos do de aprendizagem da BNCC, indicando uma tendência à instrumentalização do Programa. Muito embora tal determinação não esteja presente no edital do Pibid em 2020, ela continuou a fazer parte do edital do PRP. Essa perspectiva de se utilizar de um programa de formação para implementação das políticas curriculares pode colocar em jogo exatamente aquilo que o Pibid tem de mais inovador: a possibilidade de se pensar o currículo a partir da escola.

Além disso, consideramos que o apelo ao voluntariado em um programa de formação docente, expresso nos dois últimos editais do Pibid, encontra respaldo em uma visão do magistério como sacerdócio, algo que esperávamos ver superado depois de décadas de lutas em prol da profissionalização docente. 


\section{Conclusão}

Notamos que, no decorrer de sua existência, os editais do Pibid têm sofrido algumas modificações. Com relação aos objetivos, em geral, eles têm seguido os estabelecidos pela portaria normativa 38/2007 e reafirmados pela legislação subsequente. Objetivos complementares, inseridos em editais específicos, tiveram o propósito de vincular este, que é um programa de formação docente, às políticas educativas, como por exemplo, à avaliação em larga escala (BRASIL, 2010a, b) ou aos objetos de aprendizagem da BNCC (BRASIL, 2018).

Até 2013, os editais promoveram a expansão do Programa tanto pelo aumento do número de bolsas oferecidas quanto pela ampliação das IES elegíveis. A partir de 2018, o Programa foi fragmentado, passando a contemplar apenas licenciandos na primeira metade do curso, com o que houve diminuição do número e do tempo de duração das bolsas.

Embora apresentando um desenho próprio, o Pibid articula-se, direta ou indiretamente, com diversas políticas de formação docente e de educação básica, influenciando e sendo influenciado por tais políticas, tais como: BNCC, políticas de permanência no ensino superior e de valorização profissional etc.

Há uma quantidade enorme de estudos sobre o Pibid ou realizados nos contextos de seus projetos/subprojetos. As pesquisas citadas neste artigo representam uma ínfima parte das investigações realizadas tanto por participantes do Pibid quanto por pesquisadores externos ao Programa. Consideramos que esse conjunto de conhecimento deveria ser levado em conta na elaboração dos editais, a fim de se aperfeiçoar o Programa.

\section{Referências}

BITTENCOURT, Agueda Bernadete. Editorial. Pro-Posições, v. 19, n. 1, p. 7-13, jan./abr. 2008. Disponível em: https://www.scielo.br/j/pp/i/2008.v19n1/ . Acesso em 16 ago. 2021.

BRASIL. Fundação Coordenação de Aperfeiçoamento de Pessoal de Nível Superior. Edital CAPES/DEB n. 02/2009 - PIBID. Brasília, 2009. Disponível em:

https://www.gov.br/capes/pt-br/centrais-de-conteudo/edital02-pibid2009-pdf. Acesso em 28 jan. 2021.

BRASIL. Fundação Coordenação de Aperfeiçoamento de Pessoal de Nível Superior. Edital conjunto $n^{\circ}$ 002/2010/CAPES/SECAD-MEC - PIBID diversidade. Brasília, 2010a. Disponível em: http://uab.capes.gov.br/images/stories/download/bolsas/Edital002_2010_CapesSecad_PIBIDi versidade_1711_02.pdf. Acesso em 28 jan. 2021. 
BRASIL. Fundação Coordenação de Aperfeiçoamento de Pessoal de Nível Superior. Edital $n^{o}$ 018/2010/CAPES - PIBID. Brasília, 2010b. Disponível em: https:/ /www.gov.br/capes/ptbr/centrais-de-conteudo/edital18-pibid2010-pdf. Acesso em 28 jan. 2021.

BRASIL. Fundação Coordenação de Aperfeiçoamento de Pessoal de Nível Superior. Edital $n^{o}$ 001/2011. Programa Institucional de Bolsa de Iniciação à Docência. Brasília, 2011. Disponível em: http://www.capes.gov.br/images/stories/download/bolsas/Edital_001_PIBID_2011.pdf. Acesso em: 04 de jul. 2020.

BRASIL. Fundação Coordenação de Aperfeiçoamento de Pessoal de Nível Superior. Edital $n^{\circ}$ 011/2012. Programa Institucional de Bolsa de Iniciação à Docência. Brasília, 2012. Disponível em: https://capes.gov.br/images/stories/download/bolsas/Edital_011_Pibid-2012.pdf. Acesso em: 04 de jul. 2020.

BRASIL. Fundação Coordenação de Aperfeiçoamento de Pessoal de Nível Superior. Edital $n^{\circ}$ 061/2013. Programa Institucional de Bolsa de Iniciação à Docência. Brasília, 2013a. Disponível em: https://capes.gov.br/images/stories/download/editais/Edital_061_2013_PIBID.pdf. Acesso em: 04 de jul. 2020.

BRASIL. Fundação Coordenação de Aperfeiçoamento de Pessoal de Nível Superior. Edital $n^{\circ}$ 066/2013. Programa Institucional de Bolsa de Iniciação à Docência. Brasília, 2013b. Disponível em: https://www.gov.br/capes/pt-br/centrais-de-conteudo/edital-066-2013-pibid-diversidade692013-pdf. Acesso em 17 fev. 2021.

BRASIL. Fundação Coordenação de Aperfeiçoamento de Pessoal de Nível Superior. Edital $n^{\circ}$ 007/2018. Programa Institucional de Bolsa de Iniciação à Docência. Brasília, 2018a. Disponível em: https:/ / capes.gov.br/images/stories/download/editais/01032018-Edital-7-2018-PIBID.pdf. Acesso em: 04 de jul. 2020.

BRASIL. Fundação Coordenação de Aperfeiçoamento de Pessoal de Nível Superior. Edital $n^{o}$ 002/ 2020. Programa de Residência Pedagógica. Brasília, 2020a. Disponível em: https://www.gov.br/capes/pt-br/centrais-de-conteudo/06012019-edital-2-2020-pibid-pdf. Acesso em: 04 de jul. 2020.

BRASIL. Fundação Coordenação de Aperfeiçoamento de Pessoal de Nível Superior. Edital $n^{o}$ 002/ 2020. Programa Institucional de Bolsa de Iniciação à Docência. Brasília, 2020b. Disponível em: https://www.gov.br/capes/pt-br/centrais-de-conteudo/06012019-edital-2-2020-pibid-pdf. Acesso em: 04 de jul. 2020.

BRASIL. Fundação Coordenação de Aperfeiçoamento de Pessoal de Nível Superior. Portaria $n^{\circ}$ 38, de 28 de fevereiro de 2018. Institui o Programa de Residência Pedagógica. Brasília, 2018b.

BRASIL. Fundação Coordenação de Aperfeiçoamento de Pessoal de Nível Superior. Portaria $n^{\circ}$ 259, de 17 dezembro de 2019. Dispõe sobre o regulamento do Programa de Residência Pedagógica e do Programa Institucional de Bolsa de Iniciação à Docência (PIBID). Brasília, 2019.

BRASIL. Fundação Coordenação de Aperfeiçoamento de Pessoal de Nível Superior. Relatório de Gestão 2009-2014 (volume II). Brasília, [2015]. Disponível em: https:/ /www.gov.br/capes/ptbr/centrais-de-conteudo/20150818_DEBrelatoriodegestaovol2comanexos.pdf. Acesso em 16 fev. 2021. 
BRASIL. Fundação Coordenadoria de Aperfeiçoamento de Pessoal de Nível Superior. Relatório de Gestão. Prodocência. Brasília, 2013c.

BRASIL. Fundação Coordenadoria de Aperfeiçoamento de Pessoal de Nível Superior. Diretoria de Formação de Professores de Educação Básica. Relatório de Gestão. Pibid. Brasília, 2013d.

BRASIL. Ministério da Educação. Portaria normativa n 38, de 12 de dezembro de 2007. Dispõe sobre o Programa de Bolsa Institucional de Iniciação à Docência - PIBID. Brasília, 2007.

BRASIL. Presidência da República. Lei nº.394, de 20 de dezembro de 1996. Estabelece as diretrizes e bases da educação nacional. Brasília, 1996. Disponível em:

http://www.planalto.gov.br/ccivil_03/leis/19394.htm. Acesso em 16 fev. 2020.

BRASIL. Presidência da República. Decreto $n^{0}$ 6.755, de 29 de janeiro de 2009. Institui a Política Nacional de Formação de Profissionais do Magistério da Educação Básica, disciplina a atuação da Coordenação de Aperfeiçoamento de Pessoal de Nível Superior -CAPES no fomento a programas de formação inicial e continuada, e dá outras providências. Brasília, 2009.

BRASIL. Presidência da República. Decreto n 7.219, de 24 de junho de 2010. Dispõe sobre o Programa Institucional de Bolsa de Iniciação à Docência - PIBID e dá outras providências. Brasília, 2010.

BRASIL. Presidência da República. Lei no 11.502, de 11 de julho de 2007. Modifica as competências e a estrutura organizacional da Fundação Coordenação de Aperfeiçoamento de Pessoal de Nível Superior - CAPES. Brasília, 2007.

BRASIL. Presidência da República. Lei no 12.796, de 4 de abril de 2013. Altera a Lei no 9.394, de 20 de dezembro de 1996, que modifica as diretrizes e bases da educação nacional, para dispor sobre a formação dos profissionais da educação e dar outras providências.

CARR, Wilfred, KEMMIS, Stephen. Teoría critica de la enseñanqa: la investigación acción en la formación del professorado. Barcelona: Martinez Roca, 1988.

CHAPANI, Daisi Teresinha; LUZ, Carla Patrícia Novais. Programa Institucional de Bolsas de Iniciação à Docência: avaliação de resultados. Revista de Iniciação à Docência, v. 3, n. 1, 2018. Disponível em: https://periodicos2.uesb.br/index.php/rid/article/view/4434. Acesso em 16 ago. 2021.

CHAPANI, Daisi Teresinha; SANTOS, Tamiles Batista; RIBEIRO, Vinícius Borges. Inovação pedagógica: possibilidades vislumbradas no contexto de um subprojeto de educação em ciências. Revista de Iniciação à Docência, v. 1, n. 1, p. 37-50, 2016. Disponível em: https://periodicos2.uesb.br/index.php/rid/article/view/1591. Acesso em 16 ago. 2021.

COSTA, Celso José; DURAN, Maria Renata da Cruz. A Política Nacional de Formação de Professores entre 2005 e 2010: a nova Capes e o Sistema Universidade Aberta do Brasil. RBPG, Brasília, v. 9, n. 16, p. 263 - 313, abril de 2012. Disponível em:

https://rbpg.capes.gov.br/index.php/rbpg/article/view/289. Acesso em 16 ago. 2021. 
DINIZ-PEREIRA. Júlio Emílio. pesquisa dos educadores como estratégia para a construção de modelos críticos de formação docente. In: DINIZ-PEREIRA, J. E.; ZEICHNER, K.M. (org.) A pesquisa na formação e no trabalho docente. Belo Horizonte: Autêntica, 2002.

FETZNER, Andréa Rosana. Interculturalidade nas escolas: um estudo sobre práticas didáticas no Pibid. Educaşão \& Realidade, Porto Alegre, v. 43, n. 2, p. 513-530, abr./jun. 2018.

GATTI, Bernadete A; ANDRE, Marli E. D.; GIMENES, Nelson A. S; FERRAGUT. Laurizete. Um estudo avaliativo do Programa Institucional de Bolsa de Iniciação à Docência (Pibid). São Paulo:

Fundação Carlos Chagas, 2014.

HADDAD, Fernando. O Plano de Desenvolvimento da Educação: razões, princípios e programas. Brasília: Instituto Nacional de Estudos e Pesquisas Educacionais Anísio Teixeira, 2008.

LIMA, Everaldo José da Silva.; SILVA, Jamerson Antônio de Almeida. Analisando as concepções trabalho e formação docente nos governos Lula e Dilma através do PIBID. Revista Administração Educacional. UFPE Recife-PE, v.10. n. 1 p. 4-20, jan/jun 2019.

NOGUEIRA, Keysy Solange Costa; FERNANDEZ, Carmen. Estado da arte sobre o Pibid como espaço de formação de professores no contexto do ensino de química. Revista Ensaio, Belo Horizonte, v.21, e13136, p. 1-27, 2019.

RABELO, Leandro de Oliveira; DIAS, Valéria Silva; CARVALHO, Fernando Luiz de Campos. Mudanças no Pibid e na preparação de professores para o início da docência: análise em multiníveis baseada na THCA. Educação em Revista, Belo Horizonte, v.36, e230963, 2020.

RODRIGUES, Márcio Urel; SILVA, Luciano Duarte; MISKULIN, Rosana Giaretta S. O processo de constituição do PIBID como política pública educacional no Brasil: um panorama da legislação e dos editais. In: II CONGRESSO NACIONAL DE FORMAÇÃO DE PROFESSORES XII CONGRESSO ESTADUAL PAULISTA SOBRE FORMAÇÃO DE EDUCADORES. Águas de Lindoia-SP, 2014. Anais... Unesp. Águas de Lindoia, 2014.

RUIZ, Antonio Ibañez; RAMOS, Mozart Neves; HINGEL, Murílio. Escassez de professores no Ensino Médio: propostas estruturais e emergenciais. Brasília: MEC, 2007. Disponível em: http://portal.mec.gov.br/cne/arquivos/pdf/escassez1.pdf. Acesso em: 05 out. 2020.

SCHÖN, Donald. Formar professores como profissionais reflexivos. In: NÓVOA, António (coord.) Os professores e sua formação. Lisboa: Don Quixote, 1995

TARDIF, Maurice. Saberes Docentes e Formação Profissional. 13 ed. Petrópolis, RJ: Vozes, 2012.

VILLAS BÔAS, Fernanda Litvin Villas; D’AVILA, Daniela Lobo; MARTINS; Leila Chalub. Um estudo do Programa Institucional de Bolsa de Iniciação Docência (PIBID) a partir da abordagem da ação coletiva. Revista Perspectivas do Desenvolvimento: um enfoque multidimensional, v. 4, n.5, p. 1-25, ago.2016. 